\title{
Polycystic ovary syndrome and risks for COVID-19 infection: A comprehensive review
}

\section{PCOS and COVID-19 relationship}

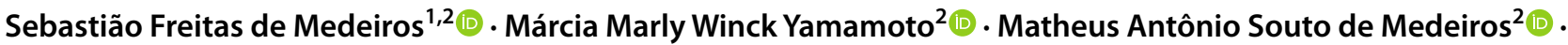 \\ Ana Karine Lin Winck Yamamoto ${ }^{2,3}$ (1) Bruna Barcelo Barbosa ${ }^{2}$ (i)
}

Accepted: 1 February 2022 / Published online: 26 February 2022

(c) The Author(s), under exclusive licence to Springer Science+Business Media, LLC, part of Springer Nature 2022

\begin{abstract}
This comprehensive review aimed to evaluate the relationship between SARS-CoV-2 infection (the cause of coronavirus disease 2019, or COVID-19) and the metabolic and endocrine characteristics frequently found in women with polycystic ovary syndrome (PCOS). In the general population, COVID-19 is more severe in subjects with dyslipidemia, obesity, diabetes mellitus, and arterial hypertension. Because these conditions are comorbidities commonly associated with PCOS, it was hypothesized that women with PCOS would be at higher risk for acquiring COVID-19 and developing more severe clinical presentations. This hypothesis was confirmed in several epidemiological studies. The present review shows that women with PCOS are at 28\%-50\% higher risk of being infected with the SARS-CoV-2 virus at all ages and that, in these women, COVID-19 is associated with increased rates of hospitalization, morbidity, and mortality. We summarize the mechanisms of the higher risk of COVID-19 infection in women with PCOS, particularly in those with carbohydrate and lipid abnormal metabolism, hyperandrogenism, and central obesity.
\end{abstract}

Keywords Polycystic ovary syndrome $\cdot$ COVID-19 $\cdot$ Obesity $\cdot$ Hyperandrogenism $\cdot$ Insulin resistance $\cdot$ Dyslipidemia

$\begin{array}{ll}\text { Abbreviations } & \\ \text { ACE2 } & \text { Angiotensin-converting enzyme 2 } \\ \text { ADAM } & \text { A disintegrin and metalloproteinase } \\ \text { Ang } & \text { Angiotensin } \\ \text { ARDS } & \text { Acute respiratory distress syndrome } \\ \text { ATIR } & \text { Angiotensin receptor 1 } \\ \text { BMI } & \text { Body mass index } \\ \text { COVID-19 } & \text { Coronavirus disease 2019 } \\ \text { CVD } & \text { Cardiovascular disease } \\ \text { DPP-4 } & \text { Dipeptidyl peptidase 4 } \\ \text { 1L } & \text { Interleukin } \\ \text { IR } & \text { Insulin resistance } \\ \text { LH } & \text { Luteinizing hormone }\end{array}$

Sebastião Freitas de Medeiros

de.medeiros@terra.com.br

1 Department of Gynecology and Obstetrics, Medical School, Federal University of Mato Grosso, Cuiabá, MT, Brazil

2 Tropical Institute of Reproductive Medicine, Cuiabá, MT, Brazil

3 University of Cuiabá, Cuiabá, MT, Brazil

$\begin{array}{ll}\text { NAFLD } & \text { Non-alcoholic fat liver disease } \\ \text { NK cell } & \text { Natural killer cell } \\ \text { PCOM } & \text { Polycystic ovary morphology } \\ \text { PCOS } & \text { Polycystic ovary syndrome } \\ \text { RAS } & \text { Renin-angiotensin system } \\ \text { SARS } & \text { Severe acute respiratory syndrome } \\ \text { SARS-CoV-2 } & \text { Severe acute respiratory syndrome corona- } \\ & \text { virus virus } 2 \\ \text { T2DM } & \text { Type 2 diabetes mellitus } \\ \text { TMPRSS2 } & \text { Transmembrane serine protease 2 } \\ \text { USA } & \text { United States of America } \\ \text { WHO } & \text { World Health Organization }\end{array}$

\section{Introduction}

Coronavirus disease 2019 (COVID-19) was declared a pandemic in March 2020 [1]. Women and young people were reported to be less affected [2, 3]. COVID-19 might be more severe and carry higher mortality rates in patients with comorbidities, such as hormone abnormalities, diabetes 
mellitus, obesity, arterial hypertension, and dyslipidemia [4-9]. Among endocrine conditions, hyperandrogenism, adrenal insufficiency, and hyperthyroidism may facilitate the acquisition of the infection and be associated with more severe clinical forms of the disease. Polycystic ovary syndrome (PCOS), diagnosed in $5 \%$ to $20 \%$ of women of reproductive age $[7,10]$, is characterized by hyperandrogenism $(70 \%-80 \%)$ and frequently accompanied by obesity $(29 \%-70 \%)$, glucose intolerance $(30 \%-40 \%)$, insulin resistance (IR) (18\%-48\%), diabetes mellitus (4\%-26\%), dyslipidemia (70\%-75\%), arterial hypertension (5\%-25\%), non-alcoholic fatty liver disease (NAFLD) (34\%-70\%), and low-grade chronic inflammation (20\%-27\%) [11-17]. This spectrum of clinical and laboratory findings in PCOS are major risks for severe COVID-19 [4, 18-20]. Because PCOS is among the most common endocrine diseases in women of reproductive age and is frequently associated with a higher risk of more severe COVID-19, this review updates the current knowledge on the subject. The need for elucidating the mechanisms of this association among the various PCOS phenotypes was also considered.

\section{Methods}

This narrative review aimed to identify possible connections between COVID-19 severity, PCOS phenotypes, and associated comorbidities. We identified the most relevant publications in the past two years in the English language. We searched PubMed, Web of Science, and Google Scholar to identify studies from December 2019 to November 2021. The search was enlarged by retrieving bibliographic citations from the obtained articles. The following major subject headings were combined: polycystic ovary syndrome and SARS-Coronavirus, PCOS and COVID-19, obesity and COVID-19, hyperandrogenism and COVID-19, IR and COVID-19, dyslipidemia and COVID-19. Abstracts were reviewed, and the most relevant complete publications were used (Fig. 1).

\section{COVID-19 prevalence, physiopathology, and risk factors}

\subsection{Prevalence and clinical manifestations}

The pandemic began in December 2019 in Wuhan, China, via zoonotic transmission of a virus from animals to humans [2]. A novel coronavirus was identified that shared substantial homology with SARS-CoV; the new virus was named SARS-Cov-2. Epidemiological data showed that COVID-19 is more frequent in men than in women and older adults than in children [21]. The worldwide
2158 records identified through database

searching from December 2019 to October

2021

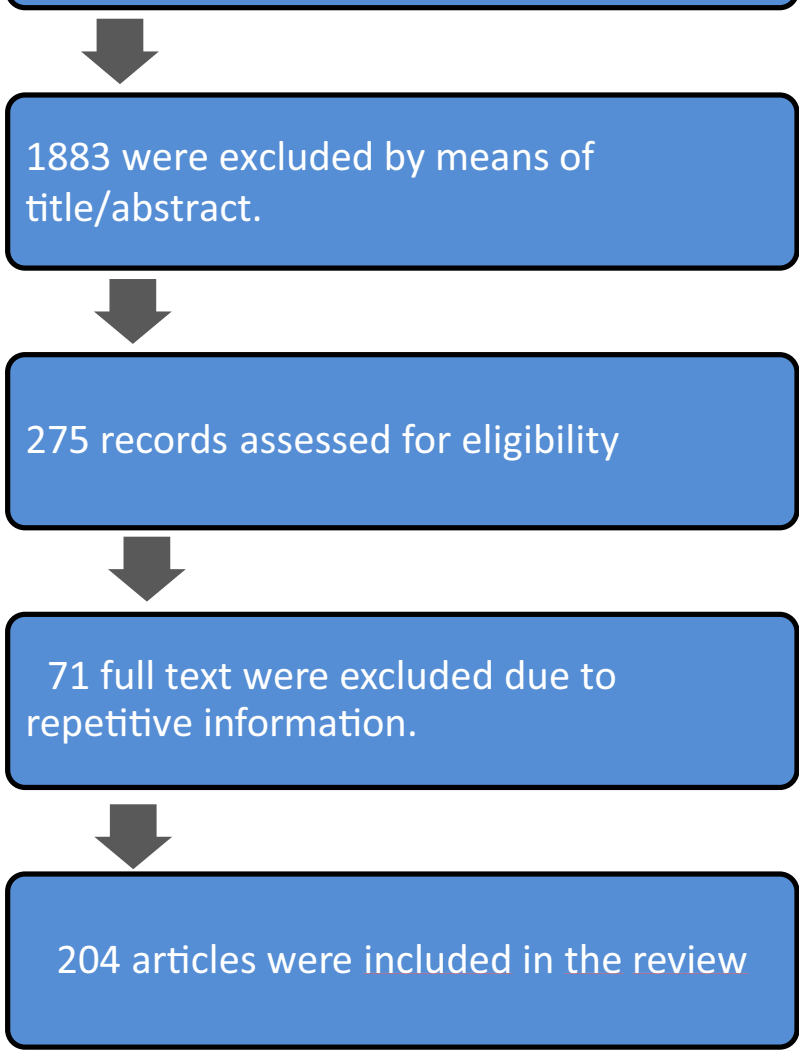

Fig. 1 Flowchart for review of the relationship between COVID-19 and polycystic ovary syndrome

case-fatality rate ranges from $2.0 \%$ [2] to $7.2 \%$ [22-24]. It is currently estimated that COVID-19 occurred in over 258 million individuals worldwide and has resulted in 5 million deaths [25]. Children represent $7 \%$ to $27 \%$ of all cases of COVID-19 but only $1.2 \%$ to $4.2 \%$ of hospitalizations [26-29].

Symptoms of COVID-19 range from entirely asymptomatic to those of a common cold to a drop in oxygen saturation, pulmonary dysfunction, and death [29]. Asymptomatic carriage has resulted in poorly defined viral prevalence rates; however, the rate is estimated at 35\% [30]. Seropositivity in these subjects had been estimated at $4.6 \%$ in the USA (ranging from $1.1 \%$ to $14.2 \%$ ) [31]. Between the ages of 18 to 44 years, about four to five cases are undiagnosed for every diagnosed case of COVID-19 [31, 32]. There is a general sequel rate of $0.30-0.43$ and 0.52 among those requiring hospitalization [32]. Older age is associated with a moderately increased risk of persistent symptoms [33], such as fatigue, dyspnea, insomnia, joint pain, and memory problems [32]. 


\subsection{Physiopathology}

SARS-CoV-2 infection causes an acute respiratory syndrome called COVID-19 (later broadened to include extrapulmonary manifestations). To enter cells, SARS-CoV-2 spike S protein requires two enzyme receptors, the angiotensin-converting enzyme 2 (ACE2) receptor and transmembrane protease serine 2 (TMPRSS2) [34-36]. SARS-CoV-2 primarily affects the respiratory system, kidneys, heart, liver, central nervous system, and coagulation system. Involvement of the cardiovascular system may be associated with microvascular obstructive thrombo-inflammatory alterations [37]. The average incubation period lasts 5 to 6 days, and the initial symptoms include fever, dry cough, runny nose, sore throat, headache, dizziness, weakness, anosmia, ageusia, vomiting, and diarrhea [25].

\subsection{Risk factors}

Many clinical abnormal conditions are thought to facilitate SARS-CoV-2 infection. It may be more frequent and severe, with increased morbidity and mortality in the context of age, gender, metabolic, cardiovascular, and endocrine diseases [5]. Despite having a lower incidence in younger and female subjects, several comorbidities may increase the risk for COVID-19 in these populations [3, 4]. COVID-19 is more severe in patients with hypertension, cardiac disease, pulmonary disease, chronic kidney disease, and liver disease [38-40]. The Center for Disease Control lists about 25 clinical-laboratory abnormalities associated with increased prevalence of COVID-19. These included cancer, diabetes mellitus, immunocompromised state, heart diseases, chronic kindly disease, chronic obstructive pulmonary disease, obesity, pregnancy, smoking, liver disease, and arterial hypertension [41]. Additionally, several endocrine conditions were associated with more frequent COVID-19. Hyperandrogenism may facilitate SARS-Cov-2 infection. For this reason, polycystic ovary syndrome (a hyperandrogenic condition) gives rise to an almost 30\% increased risk for COVID-19 compared with controls, even after adjustment for body mass index (BMI), age, and impaired glucose regulation [20].

\subsubsection{Age}

Despite infants and young children having a higher risk of respiratory tract infection, SARS-CoV-2 causes milder symptoms COVID-19 in younger people than in older patients [42, 43]. The reasons for this difference in susceptibility are not clear [2]. Children may carry smaller viral loads. It is also possible that the expression of ACE2 in lung and epithelial cells is lower in younger humans. Young people also present a qualitatively different response to the SARS-CoV-2 virus than adults, with less transition from naive $\mathrm{T}$ cells to central memory, effector, and effector memory T cells [44]. It is also possible that the simultaneous presence of other viruses in the lungs and airways in young children can compete with SARS-CoV-2, limiting its proliferation and cell invasion [2, 45]. Finally, combining these possibilities may explain why young people have a lower risk of COVID-19 than older people.

\subsubsection{Gender}

It appears that the likelihood of acquiring COVID-19 is similar in both sexes or is slightly higher in males; nevertheless, the severity of the disease is less pronounced in women than in men [3, 46-48]. Immunological and hormonal differences between men and women may explain this phenomenon [36, 49-51]. Despite identical susceptibility, severity and probability of death are higher in men, independent of age [3]. The effects of androgen levels via the expression of ACE2 and TMPRSS2 may explain the sex-specific differences in the disease severity [46, 48, 51-58]. Conversely, estradiol (and possibly progesterone) may protect women [53, 59]. Estrogens promote the production of anti-inflammatory cytokines (interleukin-10) and increase helper T and B cell numbers, thereby increasing antibody production. Estrogens suppress the production of proinflammatory cytokines and the migration of macrophages and monocytes into infected tissues [53]. Estrogens may also enhance vitamin D activity, reducing cytokine production $[60,61]$. Moreover, women mount more robust immune responses than men in clearing viral loads $[62,63]$. When vaccinated, women produce overresponses that can be twice as strong as men's [49, 64, 65]. Finally, the presence of two X chromosomes accounts for a more robust immune system that more effectively fights infections $[65,66]$.

\subsubsection{Metabolic abnormalities}

Obesity, dyslipidemia, IR, and diabetes mellitus also worsen COVID-19 [67, 68]. Obesity is characterized by adipose tissue hypoxia resulting in a chronic state of increased proinflammatory cytokines. Adipose tissue is also a target and reservoir of SARS-CoV-2 [69, 70]. The increased risk of severe COVID-19 in "Obesity" is well established [71-75]; the risks are higher for hospitalization and death $[73,76,77]$. The risk was estimated to be three-fold higher than normal-weight individuals [78]. Dyslipidemia is one of the most common comorbidities that worsen COVID19. However, it remains a matter of debate whether dyslipidemia significantly influences COVID-19 outcome [79]. Two meta-analyses found that even when controlling for age and sex, dyslipidemia increases COVID-19 severity $[40,79]$. Furthermore, treatment with statins may reduce severe disease and mortality in patients with dyslipidemia, mediated by their immune-modulatory effects [80-82]. 
Patients with diabetes mellitus have increased susceptibility to infections $[83,84]$ because of impaired immune function [85-87]. Despite SARS-CoV-2 infection in diabetic subjects being associated with adverse outcomes, it appears that the infectivity is not increased in the context of diabetes itself [88]. The hyperglycemic state participates in the pathogenesis and outcomes of respiratory infections [88-90]. Therefore, these findings suggest that patients with diabetes may experience higher viral loads when infected with respiratory viruses $[87,88]$.

\subsubsection{Endocrine diseases}

Endocrinological conditions such as thyroid dysfunction, adrenal dysfunction, and hyperandrogenism are related to increased susceptibility to acquiring COVID-19 and disease severity $[9,91,92]$. There is a direct effect of coronavirus on the thyroid gland [8]. Studies indicated that lower levels of triiodothyronine and thyroxine were found in SARS infections than controls, attributed to the destruction of follicular and parafollicular thyroid cells [91, 92]. There are few data regarding the relationship between COVID-19 infection and thyroid dysfunction [91, 93-95]. Clinical thyroid dysfunction was reported in $11 \%$ of subjects hospitalized with COVID-19: thyrotoxicosis in $94 \%$, overt hypothyroidism in 6\%, and subclinical thyroid dysfunction in 14\% [91]. Based on thyroxin stimulating hormone levels, hyperthyroidism was identified in $20 \%$ and hypothyroidism in 5\% of hospitalized patients [91]. Thyrotoxicosis in COVID-19 was associated with high proinflammatory interleukin-6 (IL6) levels and a high prevalence of thromboembolic events [91]. Thyroiditis is accompanied by hyperactivation of the Th1/Th2 response with overproduction of proinflammatory cytokines $[23,92,96]$, a pattern like the one that occurs in abnormal conditions such as COVID-19. Abnormal thyroxin stimulating hormone levels were associated with more prolonged hospitalizations and higher in-hospital mortality, primarily in women with thyrotoxicosis [91]. Regarding patients with a previous diagnosis of hyperthyroidism who were taking antithyroid medications, the risk of agranulocytosis overlapped with COVID-19, and complete blood count sare recommended if the infection is suspected [92].

Adrenal insufficiency may increase the risk of COVID-19 [97] through impaired immune function and defective neutrophil and natural killer (NK) cell activity [97]. Whether the COVID19 outcome is worsened in adrenal insufficiency is controversial [98]. It appears that COVID-19 promotes degeneration and necrosis of adrenal cortical cells through a cytopathic effect of the virus [99]. It also appears that, in the SARS-CoV-2 infection, specific amino acid sequences mimic sequences of adrenocorticotropic hormone [98]. In the case of suspicion of SARS-CoV-2 infection in patients with adrenal insufficiency, the hydrocortisone dosage might be immediately adjusted [100]. Of note, achieving physiological cortisol concentrations in patients with adrenal insufficiency and COVID-19 is challenging. Patients with Cushing's disease may also be at higher risk of COVID-19 and severe manifestations [9, 101].

As mentioned earlier, sex differences in COVID-19 suggest that men are more susceptible and have worse outcomes and mortality than women in all adult age groups [22, 50]. SARSCoV-2 spike proteins are primed by ACE2 and TMPRSS2 enzymes, which themselves are upregulated by testosterone levels [50]. Androgens may increase the risk and severity of COVID-19 [102, 103]. Nevertheless, it appears that a higher susceptibility to SARS-CoV-2 infection does not imply a higher risk of death [103]. In general, the compromised antiviral immune response to SARS-CoV-2 in men has been attributed to androgen levels [104]. Otherwise, in women, hypoestrogenism by ovariectomy or treatment with anti-estrogens increased morbidity and mortality, suggesting a protective effect of estrogen [105]. In summary, there are conflicting findings regarding the role of testosterone in COVID-19; however, testosterone modulates the transcription of the TMPRSS2 gene, inhibiting the expression of the protein required for viral entry into cells $[30,106]$. Conversely, there is also evidence that low testosterone levels might worsen COVID-19 outcomes [107, 108].

\section{COVID-19 and PCOS}

In women of reproductive age, the prevalence of PCOS ranges from 5 to $20 \%$ [7, 10], depending on age, ethnicity, and criteria used for making the diagnosis [18]. The Rotterdam criteria with the sub-classification of PCOS phenotypes are currently recommended [109]. Women with PCOS present four phenotypes according to the presence or absence of hyperandrogenism, oligo/anovulation, amenorrhea, and polycystic ovary morphology (PCOM) by ultrasound.

The phenotypes may be associated with varying proportions of comorbidities such as obesity (38\%-88\%), arterial hypertension $(5 \%-25 \%)$, glucose intolerance (30\%-40\%), IR (30\%-70\%), dyslipidemia (70\%-75\%), NAFLD (24\%-55\%), and non-alcoholic steatohepatitis (44\%). Nevertheless, the most important clinical features of PCOS are hyperandrogenemia, visceral obesity, and IR [110-112].

A clear explanation of PCOS pathophysiology is lacking. The heterogeneity of PCOS reflects several possible pathophysiologies. An increased frequency and amplitude in luteinizing hormone (LH) pulses may be found in most patients. Higher LH levels are accompanied by increased testosterone production by theca cells. The resulting hyperandrogenism may be associated with IR and hyperinsulinemia. Furthermore, a multigenic polymorphism and steroidogenic enzyme defects can be found in some women with PCOS [113, 114].

Epidemiological studies suggest that PCOS women are more susceptible to infections than women without PCOS. The 
crude incidence of COVID-19 was 18.1 per 1000 person-years among women with PCOS and 11.9 per 1000 person-years among those without $[19,20]$. A population-based study in the United Kingdom (including more than 21,000 PCOS patients with an average age of 39 years) suggested that PCOS subjects have a 51\% higher risk of COVID-19. This risk decreased to $28 \%$ after adjusting for age, BMI, and other confounding variables [19]. Despite being young and female, PCOS patients have the disadvantage of frequent comorbidities that may increase the risks of severe COVID-19 [115] (Table1).

IR associated with hyperinsulinemia, weight gain, and obesity enhances steroidogenesis and hyperandrogenism. Taken together, these features that are frequent in PCOS explain the association between PCOS and more prevalent SARS-CoV-2 infection [116] (Fig. 2). Additionally, endocrine and immune features of PCOS lead to immune dysfunction and a low-grade chronic inflammatory state [117]. Vitamin D levels are low and negatively associated with various comorbidities in PCOS. These low levels are also associated with COVID-19 [118-121].

\subsection{COVID-19in PCOS phenotypes and associated comorbidities}

The clinical relevance of PCOS phenotypes is based on anovulation, hyperandrogenemia, obesity, hyperinsulinemia, and low-grade chronic inflammation, with varying increased

Table 1 Comparable comorbidities that increase the risks for COVID-19 disease in women with and without polycystic ovary syndrome

\begin{tabular}{ll}
\hline Subjects & Comorbidities \\
\hline Non-PCOS & Hyperandrogenism \\
& Obesity \\
& Arterial hypertension \\
& Insulin resistance \\
& Hyperglycemia \\
& Dyslipidemia \\
& Liver disease \\
& Kidney disease \\
& Pulmonary disease \\
PCOS & Hyperandrogenism \\
& Obesity \\
& Arterial hypertension \\
& Insulin resistance \\
& Dysglycemia \\
& Dyslipidemia \\
& Non-alcoholic fatty liver disease \\
& Non alcoholic steatohepatitis \\
& Low-grade chronic inflammation \\
\hline & \\
& \\
& \\
& \\
&
\end{tabular}

risk for type 2 diabetes mellitus (T2DM), dyslipidemia, and cardiovascular disease (CVD); the prevalence of these conditions varies across populations [18, 122]. In other words, the clinical relevance of COVID-19 in women with PCOS might be associated with phenotypes.

\subsubsection{Hyperandrogenism}

Testosterone levels, frequently increased in PCOS subjects, inhibit immunity and controls the expression of TMPRRS2 and ACE2, facilitating viral penetration into cells of various tissues [50, 56, 58, 104, 108, 123, 124] (Fig. 3). Women with PCOS and hyperandrogenemia have a worse metabolic profile than normoandrogenemic women with PCOS $[15,16,125]$. As previously stated, androgens favor SARS-CoV-2 infection [52, 56-58, 126-130]. Studies of these phenomena in humans are supported by animal models [123]. In addition to higher susceptibility to the SARS-CoV-2 virus, women with hyperandrogenic PCOS phenotype have more pronounced symptoms than women with PCOS and normal androgen levels [131]. The role of hyperandrogenemia in COVID-19 severity is supported by the benefit of anti-androgens against severe manifestations of COVID-19 [4, 50].

\subsubsection{Obesity}

The major contributing factors for more severe clinical forms of COVID-19 in obesity are associated respiratory dysfunction [132, 133], overexpression of ACE2 in adipocytes, chronic systemic inflammation, and immune system hyperactivation $[62,134,135]$. Subjects with a BMI over $30 \mathrm{~kg} /$ $\mathrm{m}^{2}$ have a greater risk of death by COVID-19 [72, 75, 136], even after controlling for age and sex [71, 137]. In addition, obesity is associated with IR, leading to immune dysregulation characterized by amplified immune responses [138, 139], making the immune system more vulnerable to infections [140]. Increased levels of proinflammatory cytokines, NK cells, and mucosal-associated invariant $\mathrm{T}$ cells in obesity are also implicated in the pathogenesis of COVID-19 [73, 141, 142]. Additionally, higher proinflammatory dipeptidyl peptidase4 (DPP-4), and consequent hyperinsulinemia independently increase the risk of COVID-19 in obesity [143]. DPP-4 might interact with the S1 domain of the viral spike glycoprotein of SARS-CoV-2, allowing the virus to enter cells [144]. Obesity is also associated with a higher thrombosis risk relevant to coronavirus infection [145-147].

Concurrent hypoventilation and obstructive sleep apnea associated with obesity may compromise respiratory function [146, 147]. Overall, obesity might increase the risk of comorbidities such as diabetes, cardiovascular disease, and 


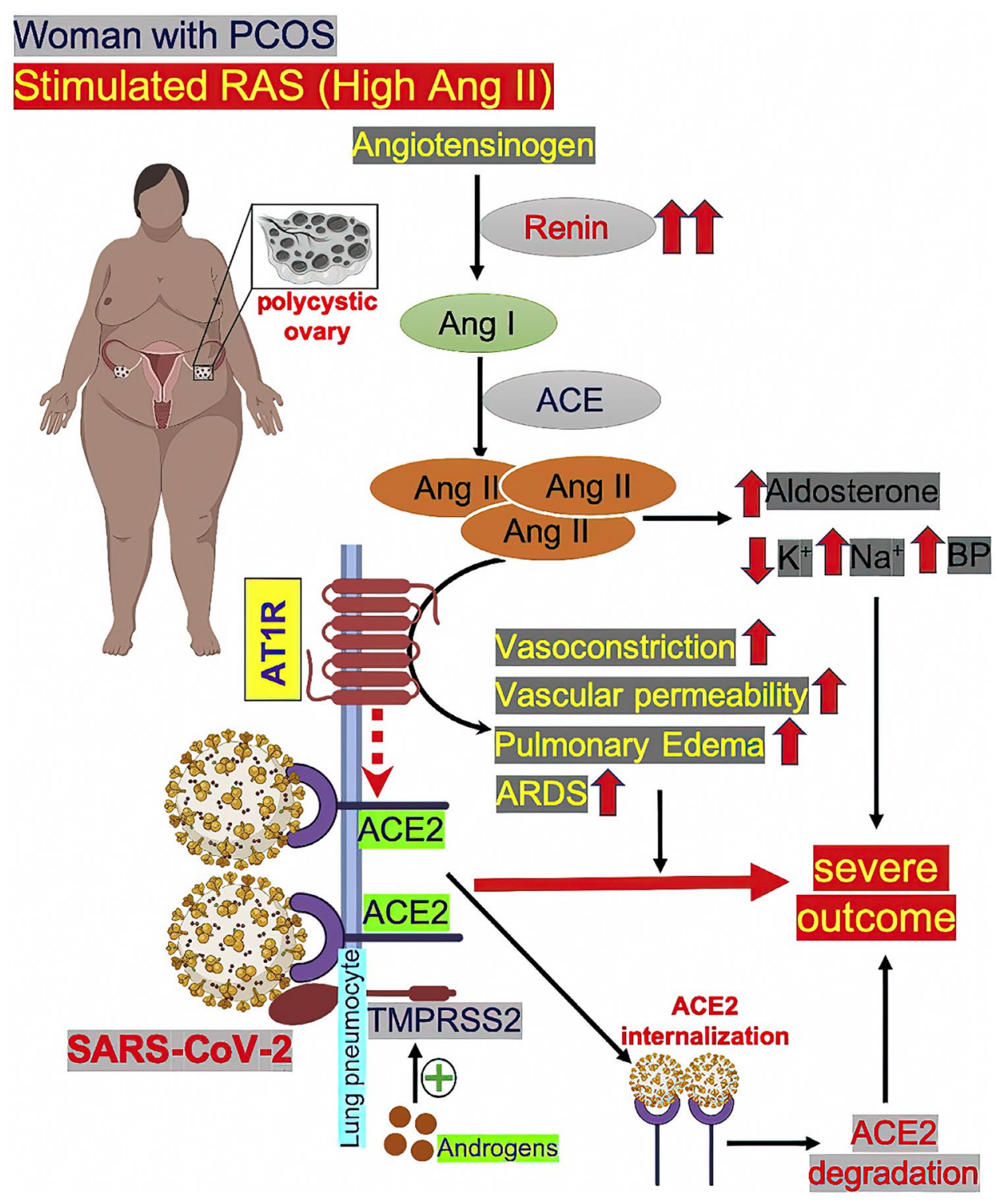

Fig. 2 In women with polycystic ovary syndrome (PCOS), plasma renin levels are high, and the renin-angiotensin system (RAS) is overactivated, leading to high amounts of Ang II. Excess Ang II causes ACE2 to dissociate from the angiotensin receptor 1 AT1R (AT1R) and bind to AT1R. The binding of angiotensin II to AT1R results in vasoconstriction, increased vascular permeability, pulmonary edema, and acute respiratory distress syndrome (ARDS). When ACE2 becomes detached from AT1R (indicated by broken red arrow), it increases the entry point for SARS-CoV-2 into pneumocytes. The viral infection might also be facilitated by overexpression of androgen-induced expression of TMPRSS2 in PCOS, as the andro-

thrombosis risk in the context of COVID-19 [148, 149]. Consequently, obesity (a common clinical feature of women with PCOS) is frequently associated with greater severity, poor outcome, and increased death rates from COVID-19 infection in these women $[22,146,150]$. The expression of gen levels are higher. Upon binding with ACE2, the SARS-CoV-2ACE2complex becomes internalized and undergoes proteasomal degradation of ACE2 inside the cell. This may cause the reduction of ACE2 levels in lung cells. High Ang II levels also stimulate the adrenal gland to increase aldosterone level, which, in turn, decreases potassium and increases sodium levels, ultimately causing increased blood pressure. Taken together, these mechanisms could result in severe outcomes inCOVID-19-infected women with PCOS (from Moin et al. [116]; Metabolism Open [115], with permission of CCCreative Commons License Deed)

ACE2 is also higher in subcutaneous and visceral adipose tissue in PCOS, permitting the cellular entrance of SARSCoV-2 [149, 151, 152]. Visceral adipose tissues in PCOS also overexpress proinflammatory cytokines, worsening COVID-19 outcome [117, 153, 154]. 
Fig. 3 Postulated mechanism of increased SARS-CoV-2 infection and worsened clinical outcomes in PCOS. In PCOS, elevated androgens upregulate the SARS-CoV-2 receptor ACE2 and modify host proteases to increase SARS-CoV-2 viral entry into tissues. The Up arrow signifies increase(s); the lightning bolt represents injury (from Lizneva et al. [122, 123], with permission of CC-Creative Commons License Deed)

\section{Polycystic Ovary Syndrome}

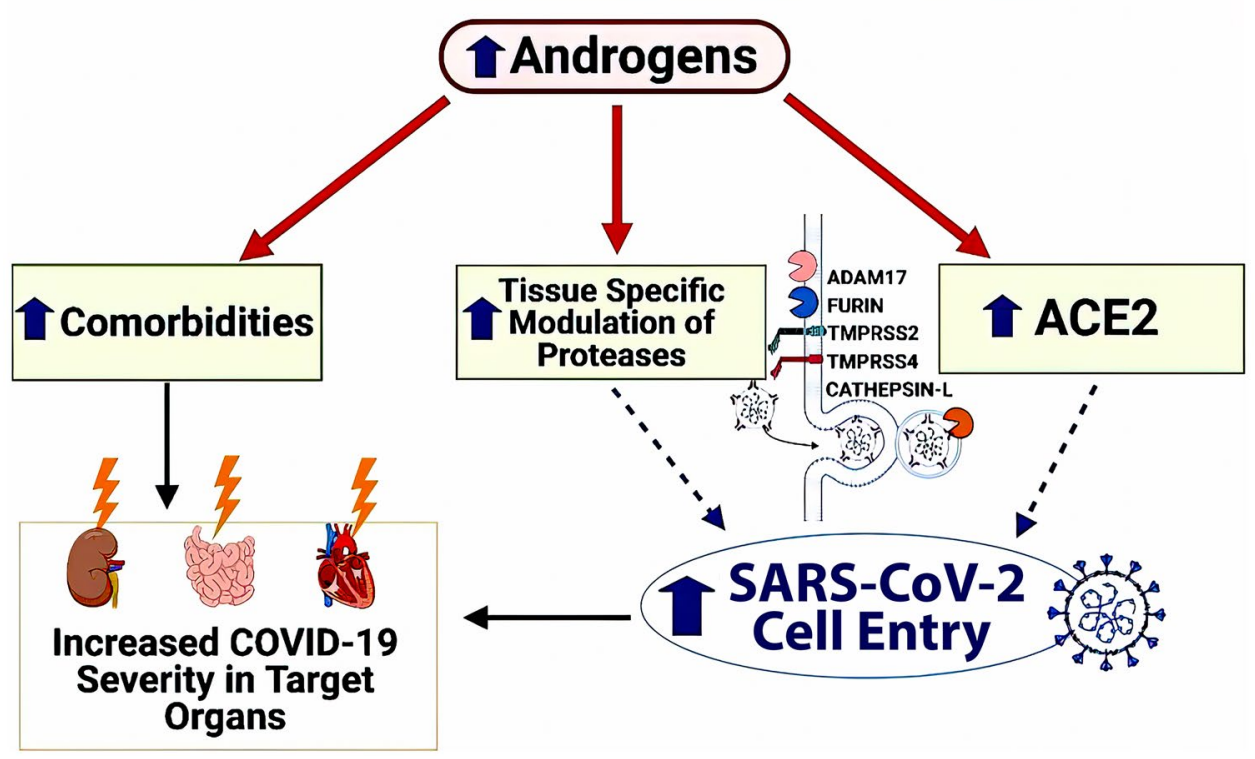

\subsubsection{IR/diabetes mellitus}

Elevated serum glucose levels in diabetes are associated with seven-fold higher morbidity and mortality from COVID-19 [85, 86, 89, 138]. Overall, IR and diabetes mellitus type 1 and 2 are risk factors for SARS-CoV-2 infection [86, 155-157]. Previously, higher expression of ACE2 in pancreatic islets was associated with diabetes mellitus [158]. Although the prevalence of COVID-19 in diabetic women does not appear to be different from that of the general population, morbidity and mortality are more significant in patients with diabetes [22, 159-163].

There are several mechanisms by which dysglycemia increases the susceptibility to severe COVID-19. These include higher affinity or more favorable cellular binding of SARSCoV-2 to ACE2 receptors, facilitating cell entry of SARSCoV-2 by increased expression of ACE2 through reduced ADAMTS 17 activity as a consequence of hyperinsulinemia [164]. There is also reduced viral clearance, upregulation of ACE2 through blockade of the renin-angiotensin system, and reduced T-cell function through defective phagocytosis by neutrophils, monocytes, and macrophages [26, 85, 86, 165-167]. There is also increased susceptibility to hyperinflammation $[138,168]$ and increased levels of DPP-4, which degrades glucagon-like peptide 1 [144]. Dysglycemia also activates plasmin and thrombin, leading to a hypercoagulable state $[169,170]$. Finally, the binding of SARS-CoV-2 to the ACE2 receptor may damage $\beta$-pancreatic cells, overwhelming the protective effect of the renin-angiotensin system, causing IR and increased SARS-CoV-2 internalization [158, 171]. The immune response is altered in hyperglycemic states, mediated by inhibiting lymphocyte proliferation and the impairment of macrophage and neutrophil functions [172, 173].

Because IR/diabetes mellitus is found in $30 \%$ to $70 \%$ of women with PCOS, they are clinical biomarkers of more severe COVID-19 in these women [174]. In PCOS, IR is associated with increased proinflammatory cytokines and higher expression levels of ACE2 [175-177]. It appears that metformin, frequently used in PCOS women with IR, has antiviral effects mediated by activation of the adenosine monophosphate-activated protein kinase pathway, modifying the ACE2 receptor, and blocking the entry of SARS-CoV-2 into cells [177, 178]. It must be noted that, in the presence of marked dehydration and renal insufficiency in severe COVID-19, metformin must be discontinued [95, 165]. In the association of PCOS with type 2 diabetes mellitus and COVID-19, DPP4 inhibitors may be used; however, insulin is the treatment of choice $[163,179]$. Of note, glucocorticoid treatment should not be used because it may aggravate glucose and metabolic homeostasis [95, 165].

\subsubsection{Dyslipidemia}

Dyslipidemia increases the severity and mortality of COVID-19 [40, 180]. Lower levels of high-density lipoprotein cholesterol preclude the stimulation of reverse cholesterol transport from the peripheral compartments to the liver, immune system modulation, and infection control. Studies have shown that lower levels of total cholesterol and low-density lipoprotein cholesterol were associated with increased COVID-19 severity [181, 182]. Investigators reported that hypercholesterolemia stimulates inflammatory 
responses and increases COVID-19 mortality [83, 84]. More robust studies are needed despite several publications supporting the higher risk of COVID-19 in dyslipidemic patients [180].

Women with PCOS have an increased risk of hyperlipidemia, non-alcoholic fatty liver disease, and central obesity, tightly associated with hyperandrogenism $[18,40,153$, 181, 182]. These conditions are associated with frequent hospitalization for COVID-19 [183]. In about 5\% of patients with COVID-19, hyperlipidemia was present [184]. Previous reports associated different SARS infections with dyslipidemia [12]. Interestingly, statin (used to treat dyslipidemia) exerts pleiotropic effects on inflammation and modulates the immune response [183]. There are reports of the effectiveness of statin treatment in some viral infections [185-187]. Whether statins may treat COVID-19 infection in dyslipidemic women with PCOS remains a hypothesis to be tested.

\subsubsection{Arterial hypertension}

Despite limited data, hypertension is considered one of the most critical risk factors for COVID-19. The loss of ACE2 through binding of SARS-CoV-2 may shift the system to higher angiotensin II and lower angiotensin (1-7) expression, activating the resin-angiotensin aldosterone system with vasoconstriction, sodium retention, oxidative stress, fibrosis, and increased baseline angiotensin levels (1-7) [50, 188, 189]. The rate of hypertension in patients with COVID19 ranges from 10 to $34 \%$ [190]. Women with PCOS have higher blood pressure than non-PCOS women, particularly in the reproductive years and those with increased serum androgen levels [18, 191-194] and activation of the reninangiotensin system [128, 190, 191]. Patients with arterial hypertension with or without PCOS have a 3-fourfold higher risk of death by COVID-19 [15, 192, 193]. In women with PCOS and COVID-19, renal complications are commonly mediated by upregulated renal ACE2 mRNA [128]. Of note, ACE blockers attenuate the risk of COVID-19 in hypertensive patients $[194,195]$.

\subsubsection{Low-grade chronic inflammation}

The risk of COVID-19 is exceptionally high in individuals with pre-existing conditions that impair immune response and amplify proinflammatory responses. Therefore, any condition involving a chronic inflammatory state may predispose a patient to acquire SARS-COV-2 and suffer a poor COVID-19 outcome [196]. Inflammation may accompany elevated BMI, obesity, hypertension, diabetes, and outcomes [197]. In summary, inflammation may facilitate severe COVID-19. The pre-existing inflammatory condition in PCOS renders patients more susceptible to activating proinflammatory pathways in response to infections [198], irrespective of total fat mass [199]. Central obesity in PCOS with dysfunctional adipocytes correlates with marked adipose tissue overproduction of cytokines [17] and the chronic inflammatory state [18], favoring COVID-19 in women with PCOS [200].

\subsubsection{Vitamin D deficiency}

Vitamin D influences innate and adaptative immune responses that regulate IL-6, and it inhibits the release of proinflammatory cytokines from macrophages in response to various viruses $[118,119,201]$. Lower vitamin D levels have been associated with an impaired immune system and a higher risk for COVID-19 [202]. Because about 60\% of women with PCOS have vitamin D deficiency [203], it is expected that a decrease in vitamin D levels will lead these patients to a higher risk of severe COVID-19 [201]. In PCOS, decreased vitamin D levels are associated with factors related to systemic macrophage-derived cytokine panels $[117,118,204]$. Additionally, vitamin D supplementation was shown to reduce the risk of COVID-19 via impairment of macrophage maturation and decreased serum levels of proinflammatory cytokines $[118,119]$.

\section{Concluding remarks}

COVID-19 has been consistently reported to be more severe and fatal in the presence of comorbidities. Young age and female sex appear to be protective factors. Obesity, type 2 diabetes mellitus, and arterial hypertension are significant predisposing factors. The low-grade chronic inflammatory state is the core component linking these underlining conditions to poor COVID-19 outcomes. Some endocrinological dysfunctions also facilitate SARS-CoV-2 infection and COVID-19 severity, particularly hyperandrogenism and thyrotoxicosis. Considering that a chronic inflammatory state is found in nearly $30 \%$ of PCOS patients, COVID-19 therapy must be tailored for women with PCOS. The hyperandrogenism present in $80 \%$ of PCOS patients inhibits immunity and controls the expression of TMPRRS2 and ACE2, facilitating viral prescription into cells. Prescription of antiandrogens appears to have a beneficial effect on COVID-19 manifestations.

Obesity (the major contributing factor for severe COVID-19) is associated with amplified immune responses, increased proinflammatory cytokine levels, higher levels of DPP-4, and hyperinsulinemia. Because obesity is found in $30 \%-70 \%$ of women with PCOS, SARS-CoV-2 infection in PCOS requires specific management of concurrent IR. The prescription of metformin for these patients appears to modify the ACE2 receptor and block the entry of SARSCoV-2 into cells. Hypercholesterolemia appears to increase 
the severity of COVID-19 infection and dyslipidemia, which is found in two-thirds of women with PCOS and is closely associated with hyperandrogenism, NAFLD, and central obesity (conditions frequently associated with PCOS). Hypercholesterolemia stimulates the inflammatory response and increases COVID-19 mortality. Statins may modulate inflammation and immune responses; their use in COVID-19 in women with PCOS needs to be investigated. It is plausible to conclude that the association between COVID-19 infection and PCOS syndrome results in more severe clinical manifestations. Specific protocols for caring for these patients must be developed.

\section{Declarations}

Conflict of interest The authors declare there are no financial or other conflicts of interest that could be perceived as prejudicing the impartiality of this study.

\section{References}

1. World Health Organization. Statement on the second meeting of the International Health Regulations. Emergency Committee regarding the outbreak of novel coronavirus (2019-nCoV). 2005. https://www. who.int/news-room/detail/30-01-2020-statement-on-the-secondmeeting-of-the-international-health-regulations-(2005)-emergencycommittee-regarding-the-outbreak-of-novel-coronavirus-(2019-ncov. (Assessed $12 \mathrm{Jul}$ 2021).

2. Yuki K, Fujiogi M, Koutsogiannaki S. COVID-19 pathophysiology: A review. Clin Immunol. 2020;215:108427.

3. Jin JM, Bai P, He W, Wu F, Liu XF, Han DM, et al. Gender Differences in Patients With COVID-19: Focus on Severity and Mortality. Front Public Health. 2020;8:152.

4. Kyrou I, Karteris E, Robbins T, Chatha K, Drenos F, Randeva HS. Polycystic ovary syndrome (PCOS) and COVID-19: an overlooked female patient population at potentially higher risk during the COVID-19 pandemic. BMC Med. 2020;18:220.

5. Klonoff DC, Umpierrez GE. Letter to the Editor: COVID-19 in patients with diabetes: Risk factors that increase morbidity. Metabolism. 2020;108:154224.

6. Zuin M, Rigatelli G, Zuliani G, Rigatelli A, Mazza A, Roncon L. Arterial hypertension and risk of death in patients with COVID19 infection: Systematic review and meta-analysis. J Infect. 2020;81:e84-6.

7. Azziz R, Sanchez LA, Knochenhauer ES, Moran C, Lazenby J, Stephens KC, et al. Androgen excess in women: experience with over 1000 consecutive patients. J Clin Endocrinol Metab. 2004;89:453-62.

8. Scappaticcio L, Pitoia F, Esposito K, Piccardo A, Trimboli P. Impact of COVID-19 on the thyroid gland: an update. Rev EndocrMetabDisord. 2021;22:803-15.

9. Guarnotta V, Ferrigno R, Martino M, et al. Glucocorticoid excess and COVID-19 disease. Rev EndocrMetabDisord. 2021;22:703-14.

10. March WA, Moore VM, Willson KJ, Phillips DI, Norman RJ, Davies MJ. The prevalence of polycystic ovary syndrome in a community sample assessed under contrasting diagnostic criteria. Hum Reprod. 2010;25:544-51.
11. Legro RS, Kunselman AR, Dunaif A. Prevalence and predictors of dyslipidemia in women with polycystic ovary syndrome. Am J Med. 2001;111:607-13.

12. De Leo V, Musacchio MC, Palermo V, Di Sabatino A, Morgante G, Petraglia F. Polycystic ovary syndrome and metabolic comorbidities: therapeutic options. Drugs Today (Barc). 2009;45:763-75.

13. Ruan X, Dai Y. Study on chronic low-grade inflammation and influential factors of polycystic ovary syndrome. Med PrincPract. 2009; 18:118-22.

14. Wu Q, Zhou L, Sun X, Yan Z, Hu C, Wu J, et al. Altered lipid metabolism in recovered SARS patients twelve years after infection. Sci Rep. 2017;7:9110.

15. Glintborg D, Rubin KH, Nybo M, Abrahamsen B, Andersen M. Cardiovascular disease in a nationwide population of Danish women with polycystic ovary syndrome. Cardiovasc Diabetol. 2018;17:37.

16. Ganie MA, Vasudevan V, Wani IA, Baba MS, Arif T, Rashid A. Epidemiology, pathogenesis, genetics \& management of polycystic ovary syndrome in India. Indian J Med Res. 2019; 150:333-44.

17. de Medeiros SF, Rodgers RJ, Norman RJ. Adipocyte and steroidogenic cell cross-talk in polycystic ovary syndrome. Hum Reprod Update. 2021;27:771-96.

18. de Medeiros SF, Yamamoto MMW, Souto de Medeiros MA, Barbosa BB, Soares JM, Baracat EC. Changes in clinical and biochemical characteristics of polycystic ovary syndrome with advancing age. Endocr Connect. 2020;9:74-89.

19. Alahmadi AA. The common pathological factors between polycystic ovary syndrome and COVID-19 infection: A review. Biosc Biotech Res Comm. 2020;13:1708-16.

20. Subramanian A, Anand A, Adderley NJ, Okoth K, Toulis KA, Gokhale K, et al. Increased COVID-19 infections in women with polycystic ovary syndrome: a population-based study. Eur J Endocrinol. 2021;184:637-45.

21. Ballering AV, Oertelt-Prigione S, Olde Hartman TC, Rosmalen JGM. Lifelines corona research initiative. Sex and genderrelated differences in COVID-19 diagnoses and SARS-CoV-2 testing practices during the first wave of the pandemic: The Dutch lifelines COVID-19 Cohort Study. J Womens Health (Larchmt). 2021;30:1686-1692.

22. Chen N, Zhou M, Dong X, Qu J, Gong F, Han Y, et al. Epidemiological and clinical characteristics of 99 cases of 2019 novel coronavirus pneumonia in Wuhan, China: a descriptive study. Lancet. 2020;395:507-13.

23. Wu D, Yang XO. TH17 responses in cytokine storm of COVID-19: An emerging target of JAK2 inhibitor Fedratinib. J Microbiol Immunol Infect. 2020;53:368-70.

24. Onder G, Rezza G, Brusaferro S. Case-fatality rate and characteristics of patients dying in relation to COVID-19 in Italy. JAMA. 2020;323:1775-6.

25. World Health Organization. WHO, coronavirus (COVID-19) dashboard vaccination date. 2021.

26. Leeb RT, Price S, Sliwa S, et al. COVID-19 Trends among school-aged children - United States, 1 Mar - 19 Sep 2020. MMWR Morb Mortal Wkly Rep. 2020;69:1410-5.

27. Ding Y, Yan Hand Guo W. Clinical characteristics of children with COVID-19: a meta-analysis. Front Pediatr. 2020;8:431.

28. Gudbjartsson DF, Helgason A, Jonsson H, et al. Spread of SARS-CoV-2 in the Icelandic population. N Engl J Med. 2020;382:2302-15.

29. Badal S, Thapa Bajgain K, Badal S, Thapa R, Bajgain BB, Santana MJ. Prevalence, clinical characteristics, and outcomes of pediatric COVID-19: A systematic review and meta-analysis. J Clin Virol. 2021;135:104715.

30. Sah P, Fitzpatrick MC, Zimmer CF, et al. Asymptomatic SARSCoV-2 infection: A systematic review and meta-analysis. Proc Natl Acad Sci U S A. 2021;118:e2109229118. 
31. Kalish H, Klumpp-Thomas C, Hunsberger S, Baus HA, Fay MP, Siripong N, Wang J, Hicks J, Mehalko J, Travers J, et al. Undiagnosed SARS-CoV-2 seropositivity during the first 6 months of the COVID-19 pandemic in the United States. Sci Transl Med. 2021;13(601):eabh3826.

32. Chen, MA, Haupert RS, Zimmerman L, BSc, Shi X, PhD, Fritsche LG, PhD, Mukherjee B, PhD. Global prevalence of post-acute sequelae of COVID-19 (PASC) or long COVID: A meta-analysis and systematic review. 2021

33. Perlis RH, Green J, Santillana M, et al. Persistence of symptoms up to 10 months following acute COVID-19 illness. Preprint. medRxiv. 2021;2021.03.07.21253072. Published 8 Mar 2021.

34. Ni W, Yang X, Yang D, Bao J, Li R, Xiao Y, et al. Role of angiotensin-converting enzyme 2 (ACE2) in COVID-19. Crit Care. 2020;24:22.

35. Shang J, Wan Y, Luo C, Ye G, Geng Q, Auerbach A, et al. Cell entry mechanisms of SARS-CoV-2. Proc Natl Acad Sci U S A. 2020;117:11727-34.

36. Bohn MK, Hall A, Sepiashvili L, Jung B, Steele S, Adeli K. Pathophysiology of COVID-19: Mechanisms underlying disease severity and progression. Physiology (Bethesda). 2020;35:288-301.

37. Ciceri F, Beretta L, Scandroglio AM, Colombo S, Landoni G, Ruggeri A, et al. Microvascular COVID-19 lung vessels obstructive thromboinflammatory syndrome (MicroCLOTS): an atypical acute respiratory distress syndrome working hypothesis. Crit Care Resusc. 2020;22:95-7.

38. Yonas E, Alwi I, Pranata R, Huang I, Lim MA, Gutierrez EJ, et al. Effect of heart failure on the outcome of COVID-19 A meta analysis and systematic review. Am J Emerg Med. 2020;S0735-6757(20):30602-11.

39. Pranata R, Supriyadi R, Huang I, Permana H, Lim MA, Yonas $\mathrm{E}$, et al. The association between chronic kidney disease and new onset renal replacement therapy on the outcome of COVID-19 patients: A meta-analysis. Clin Med Insights Circ Respir Pulm Med. 2020;14:1179548420959165.

40. Choi GJ, Kim HM, Kang H. The potential role of dyslipidemia in COVID-19 severity: An umbrella review of systematic reviews. J Lipid Atheroscler. 2020;9:435-48.

41. Cennimo DJ. Bronze MS. Coronavirus disease 2019 (COVID19). 2021, Emedicine Medscape. 2021;2500114-print.

42. Dong Y, Mo X, Hu Y, et al. Epidemiology of COVID-19 among children in China. Pediatrics. 2020;145:e20200702.

43. Livingston E, Bucher K. Coronavirus disease 2019 (COVID-19) in Italy. JAMA. 2020;323:1335.

44. Saule P, Trauet J, Dutriez V, Lekeux V, Dessaint JP, Labalette M. Accumulation of memory T cells from childhood to old age: central and effector memory cells in CD4(+) versus effector memory and terminally differentiated memory cells in CD8(+) compartment. Mech Ageing Dev. 2006;127:274-81.

45. Nickbakhsh S, Mair C, Matthews L, Reeve R, Johnson PCD, Thorburn F, et al. Virus-virus interactions impact the population dynamics of influenza and the common cold. Proc Natl Acad Sci U S A. 2019;116:27142-50.

46. Wray S, Arrowsmith S. The physiological mechanisms of the sex-based difference in outcomes of COVID19 infection. Front Physiol. 2021;12:627260.

47. Grasselli G, Zangrillo A, Zanella A, Antonelli M, Cabrini L, Castelli A, et al. Baseline characteristics and outcomes of 1591 patients infected with SARS-CoV-2 admitted to ICUs of the lombardy region. Italy JAMA. 2020;323:1574-81.

48. Tejpal A, Gianos E, Cerise J, Hirsch JS, Rosen S, Kohn N, et al. Sex-based differences in COVID-19 outcomes. J Womens Health (Larchmt). 2021;30:492-501.
49. Bunders MJ, Altfeld M. Implications of sex differences in immunity for SARS-CoV-2 pathogenesis and design of therapeutic interventions. Immunity. 2020;53:487-95.

50. Mohamed MS, Moulin TC, Schiöth HB. Sex differences in COVID-19: the role of androgens in disease severity and progression. Endocrine. 2021;71:3-8.

51. Foresta C, Rocca MS, Di Nisio A. Gender susceptibility to COVID-19: a review of the putative role of sex hormones and $\mathrm{X}$ chromosome. J Endocrinol Invest. 2021;44:951-6.

52. Salonia A, Corona G, Giwercman A, Maggi M, Minhas S, Nappi $\mathrm{RE}$, et al. SARS-CoV-2, testosterone and frailty in males (PROTEGGIMI): A multidimensional research project. Andrology. 2021;9:19-22.

53. Strope JD, Chau CH, Figg WD. Are sex discordant outcomes in COVID-19 related to sex hormones? Semin Oncol. 2020;47:335-40.

54. Gagliardi MC, Tieri P, Ortona E, Ruggieri A. ACE2 expression and sex disparity in COVID-19. Cell Death Discov. 2020;6:37. Published 26 May 2020. https://doi.org/10.1038/ s41420-020-0276-1.

55. Baratchian M, McManus JM, Berk MP, et al. Androgen regulation of pulmonary AR, TMPRSS2 and ACE2 with implications for sex-discordant COVID-19 outcomes. Sci Rep. 2021;11(1):111302020;27:E1-3.

56. Sharifi N, Ryan CJ. Androgen hazards with COVID-19. Endocr Relat Cancer. 2020;27:E1-3.

57. Wambier CG, Goren A. Severe acute respiratory syndrome coronavirus 2 (SARS-CoV-2) infection is likely to be androgen mediated. J Am Acad Dermatol. 2020;83:308-9.

58. Wambier CG, Goren A, Vaño-Galván S, Ramos PM, Ossimetha A, Nau G, et al. Androgen sensitivity gateway to COVID-19 disease severity. Drug Dev Res. 2020;81:771-6.

59. Gotluru C, Roach A, Cherry SH, Runowicz CD. Sex, hormones, immune functions, and susceptibility to coronavirus disease 2019 (COVID-19)-related morbidity. Obstet Gynecol. 2021;137:423-9.

60. Mauvais-Jarvis F, Klein SL, Levin ER. Estradiol, progesterone, immunomodulation, and COVID-19 outcomes. Endocrinology. 2020;161:bqaa127.

61. Pagano MT, Peruzzu D, Ruggieri A, Ortona E, Gagliardi MC. Vitamin D and sex differences in COVID-19. Front Endocrinol (Lausanne). 2020;11:567824.

62. Kruglikov IL, Scherer PE. The role of adipocytes and adipocytelike cells in the severity of COVID-19 infections. Obesity (Silver Spring). 2020;28:1187-90.

63. Klein SL, Flanagan KL. Sex differences in immune responses. Nat Rev Immunol. 2016;16:626-38.

64. Klein SL, Jedlicka A, Pekosz A. The Xs and Y of immune responses to viral vaccines. Lancet Infect Dis. 2010;10:338-49.

65. Chang WH. A review of vaccine effects on women in light of the COVID-19 pandemic. Taiwan J Obstet Gynecol. 2020;59:812-20.

66. Schurz H, Salie M, Tromp G, Hoal EG, Kinnear CJ, Möller M. The $\mathrm{X}$ chromosome and sex-specific effects in infectious disease susceptibility. Hum Genomics. 2019;13:2.

67. Malavazos AE, Corsi Romanelli MM, Bandera F, Iacobellis G. Targeting the adipose tissue in COVID-19. Obesity (Silver Spring). 2020;28:1178-9.

68. Ryan PM, Caplice NM. Is adipose tissue a reservoir for viral spread, immune activation, and cytokine amplification in coronavirus disease 2019? Obesity (Silver Spring). 2020;28:1191-4.

69. Muscogiuri G, Pugliese G, Barrea L, Savastano S, Colao A. Commentary: Obesity: The achilles heel for COVID-19? Metabolism. 2020;108:154251. 
70. Dietz W, Santos-Burgoa C. Obesity and its implications for COVID-19 mortality. Obesity (Silver Spring). 2020;28:1005.

71. Popkin BM, Du S, Green WD, Beck MA, Algaith T, Herbst CH, et al. Individuals with obesity and COVID-19: A global perspective on the epidemiology and biological relationships. Obes Rev. 2020;21:e13128.

72. Gao M, Piernas C, Astbury NM, Hippisley-Cox J, O'Rahilly $\mathrm{S}$, Aveyard $\mathrm{P}$, et al. Associations between body-mass index and COVID-19 severity in 6.9 million people in England: a prospective, community-based, cohort study. Lancet Diabetes Endocrinol. 2021;9:350-9.

73. De Lorenzo A, Estato V, Castro-Faria-Neto HC, Tibirica E. Obesityrelated inflammation and endothelial dysfunction in COVID-19: Impact on disease severity. J Inflamm Res. 2021;14:2267-76.

74. Brandão SCS, Godoi ETAM, de Oliveira Cordeiro LH, Bezerra CS, de Oliveira Xavier Ramos J, de Arruda GFA, et al. COVID19 and obesity: the meeting of two pandemics. Arch Endocrinol Metab. 2020:2359-3997000000318.

75. Hoong CWS, Hussain I, Aravamudan VM, Phyu EE, Lin JHX, Koh H. Obesity is associated with poor covid-19 outcomes: A systematic review and meta-analysis. HormMetab Res. 2021;53:85-93.

76. Garg S, Kim L, Whitaker M, O'Halloran A, Cummings C, Holstein R, et al. Hospitalization rates and characteristics of patients hospitalized with laboratory-confirmed coronavirus disease 2019 - COVID-NET, 14 states, 2020. MMWR Morb Mortal Wkly Rep. 2020;69:458-64.

77. Richardson S, Hirsch JS, Narasimhan M, Crawford JM, McGinn T, Davidson KW, et al. Presenting characteristics, comorbidities, and outcomes among 5700 patients hospitalized With COVID-19 in the New York City area. JAMA. 2020;323:2052-9.

78. Lighter J, Phillips M, Hochman S, Sterling S, Johnson D, Francois F, et al. Obesity in patients younger than 60 years is a risk factor for COVID-19 hospital admission. Clin Infect Dis. 2020;71(15):896-7.

79. Atmosudigdo IS, Pranata R, Lim MA, Henrina J, Yonas E, Vania $\mathrm{R}$, et al. Dyslipidemia increases the risk of severe COVID-19: A systematic review, meta-analysis, and meta-regression. J Clin Exp Hepatol. 2021. https://doi.org/10.1016/j.jceh.2021.01.007.

80. Daniels LB, Sitapati AM, Zhang J, Zou J, Bui QM, Ren J, et al. Relation of statin use prior to admission to severity and recovery among COVID-19 inpatients. Am J Cardiol. 2020;136:149-55.

81. Castiglione V, Chiriacò M, Emdin M, Taddei S, Vergaro G. Statin therapy in COVID-19 infection. Eur Heart J Cardiovasc Pharmacother. 2020;6:258-9.

82. Kow CS, Hasan SS. Meta-analysis of effect of statins in patients with COVID-19. Am J Cardiol. 2020;134:153-5.

83. Sorokin AV, Karathanasis SK, Yang ZH, Freeman L, Kotani $\mathrm{K}$, et al. COVID-19-Associated dyslipidemia: Implications for mechanism of impaired resolution and novel therapeutic approaches. FASEB J. 2020;34(8):9843-53.

84. Hariyanto TI, Kurniawan A. Dyslipidemia is associated with severe coronavirus disease 2019 (COVID-19) infection. DibetMetab Syndrome: Clin Res Rev. 2020;14:1463-5.

85. Hodgson K, Morris J, Bridson T, Govan B, Rush C, Ketheesan $\mathrm{N}$. Immunological mechanisms contributing to the double burden of diabetes and intracellular bacterial infections. Immunology. 2015;144:171-85.

86. Muller LM, Gorter KJ, Hak E, Goudzwaard WL, Schellevis FG, Hoepelman AI, et al. Increased risk of common infections in patients with type 1 and type 2 diabetes mellitus. Clin Infect Dis. 2005;41:281-8.

87. Hill MA, Mantzoros C, Sowers JR. Commentary: COVID-19 in patients with diabetes. Metabolism. 2020;107:154217.

88. Adini GP, Morieri ML, Longato E, Avogaro A. Prevalence and impact of diabetes among people infected with SARS-CoV-2. J Endocrinol Invest. 2020;43:867-9.
89. Sardu C, D’Onofrio N, Balestrieri ML, Barbieri M, Rizzo MR, Messina V, et al. Outcomes in patients with hyperglycemia affected by COVID-19: Can we do more on glycemic control? Diabetes Care. 2020;43:1408-15.

90. Morra ME, Van Thanh L, Kamel MG, Ghazy AA, Altibi AMA, Dat LM, et al. Clinical outcomes of current medical approaches for Middle East respiratory syndrome: A systematic review and meta-analysis. Rev Med Virol. 2018;28:e1977.

91. Pal R, Banerjee M. COVID-19 and the endocrine system: exploring the unexplored. J Endocrinol Invest. 2020;43:1027-31.

92. Lania A, Sandri MT, Cellini M, Mirani M, Lavezzi E, Mazziotti G. Thyrotoxicosis in patients with COVID-19: the THYRCOV study. Eur J Endocrinol. 2020;183:381-7.

93. Mazziotti G, Sorvillo F, Naclerio C, Farzati A, Cioffi M, Perna $\mathrm{R}$, et al. Type- 1 response in peripheral CD4+ and CD8+ T cells from patients with Hashimoto's thyroiditis. Eur J Endocrinol. 2003;148:383-8.

94. Clausen CL, Rasmussen ÅK, Johannsen TH, et al. Thyroid function in COVID-19 and the association with cytokine levels and mortality. Endocr Connect. 2021;10:1234-42.

95. Borntein SR, Rubino F, Khunti K, Mingrone G, Hopkins D, Birkenfeld Al, et al. Practical recommendations for the management of diabetes in patients with COVID-19. Lancet Diabetes Endocrinol. 2020a;8:546-50.

96. Yao XH, Li TY, He ZC, Ping YF, Liu HW, Yu SC, et al. A pathological report of three COVID-19 cases by minimal invasive autopsies. Zhonghua Bing Li Xue Za Zhi. 2020;49:411-7.

97. Bancos I, Hazeldine J, Chortis V, Hampson P, Taylor AE, Lord JM, et al. Primary drenal insufficiency is associated with impaired natural killer cell function: a potential link to increased mortality. Eur J Endocrinol. 2017;176:471-80.

98. Arlt W, Baldeweg SE, Pearce SHS, Simpson HL. Endocrinology in the time of COVID-19: Management of adrenal insufficiency. Eur J Endocrinol. 2020;183:G25-32.

99. Wheatland R. Molecular mimicry of ACTH in SARS - implications for corticosteroid treatment and prophylaxis. Med Hypotheses. 2004;63:855-62.

100. Arlt W. Society for endocrinology clinical committee. Society for endocrinology endocrine emergency guidance: Emergency management of acute adrenal insufficiency (adrenal crisis) in adult patients. Endocr Connect. 2016;5:G1-3.

101. Newell-Price J, Nieman LK, Reincke M, Tabarin A. Endocrinology in the time of COVID-19: Management of cushing's syndrome. Eur J Endocrinol. 2020;183:G1-7.

102. Goren A, McCoy J, Wambier CG, Vano-Galvan S, Shapiro J, Dhurat R, et al. What does androgenetic alopecia have to do with COVID-19? An insight into a potential new therapy. Dermatol Ther. 2020a;33:e13365.

103. Goren A, Vaño-Galván S, Wambier CG, McCoy J, Gomez-Zubiaur A, Moreno-Arrones OM, et al. A preliminary observation: Male pattern hair loss among hospitalized COVID-19 patients in Spain - A potential clue to the role of androgens in COVID-19 severity. $\mathrm{J}$ Cosmet Dermatol. 2020;19:1545-7.

104. Auerbach JM, Khera M. Testosterone's Role in COVID-19. J Sex Med. 2021;18:843-8.

105. Channappanavar R, Fett C, Mack M, Ten Eyck PP, Meyerholz DK, Perlman S. Sex-based differences in susceptibility to severe acute respiratory syndrome coronavirus infection. J Immunol. 2017;198:4046-53.

106. Stopsack KH, Mucci LA, Antonarakis ES, Nelson PS, Kantoff PW. TMPRSS2 and COVID-19: Serendipity or opportunity for intervention? Cancer Discov. 2020;10:779-82.

107. Younis JS, Skorecki K, Abassi Z. The double edge sword of testosterone's role in the COVID-19 pandemic. Front Endocrinol (Lausanne). 2021;12:607179. 
108. Niemann PJ, Goldstein HV. Testosterone in COVID-19: Friend or foe? Endocrine. 2021;71:281-2.

109. Azziz R, Carmina E, Dewailly D, et al. Positions statement: criteria for defining polycystic ovary syndrome as a predominantly hyperandrogenic syndrome: An androgen excess society guideline. J Clin Endocrinol Metab. 2006;91:4237-45.

110. Norman RJ, Dewailly D, Legro RS, Hickey TE. Polycystic ovary syndrome. Lancet. 2007;370:685-97.

111. De Medeiros SF, Barbosa JS, Yamamoto MM. Comparison of steroidogenic pathways among normoandrogenic and hyperandrogenic polycystic ovary syndrome patients and normal cycling women. J ObstetGynaecol Res. 2015;41:254-63.

112. Kahal H, Kyrou I, Uthman OA, et al. The prevalence of obstructive sleep apnoea in women with polycystic ovary syndrome: a systematic review and meta-analysis. Sleep Breath. 2020;24:339-50.

113. Tsilchorozidou T, Overton C, Conway GS. The pathophysiology of polycystic ovary syndrome. Clin Endocrinol (Oxf). 2004;60:1-17.

114. Yamamoto MMW, de Medeiros SF. Differential activity of the corticosteroidogenic enzymes in normal cycling women and women with polycystic ovary syndrome. Rev Endocr Metab Disord. 2019;20:3-13.

115. Gilbert EW, Tay CT, Hiam DS, Teede HJ, Moran LJ. Comorbidities and complications of polycystic ovary syndrome: An overview of systematic reviews. Clin Endocrinol (Oxf). 2018;89:683-99.

116. Moin ASM, Sathyapalan T, Butler AE, Atkin SL. Vitamin D association with macrophage-derived cytokines in polycystic ovary syndrome: An enhanced risk of COVID-19 infection?. Front Endocrinol (Lausanne). 2021;12:638621.

117. Morgante G, Troìa L, De Leo V. Coronavirus disease 2019 (SARS-CoV-2) and polycystic ovarian disease: Is there a higher risk for these women? J Steroid Biochem Mol Biol. 2021;205:105770.

118. Reis G, Dos OP, Gontijo N, Rodrigues K, Alves M, Ferreira $\mathrm{C}$, et al. Vitamin D receptor polymorphisms and the polycystic ovary syndrome: A systematic review. J Obstet Gynaecol Res. 2017;43:436-46.

119. Azadi-Yazdi M, Nadjarzadeh A, Khosravi-Boroujeni H, SalehiAbargouei A. The effect of vitamin D supplementation on the androgenic profile in patients with polycystic ovary syndrome: A systematic review and meta-analysis of clinical trials. Horm Metab Res. 2017;49:174-9.

120. Grant W, Lahore H, McDonnell S, Baggerly C, French C, Aliano $\mathrm{J}$, et al. Evidence that vitamin D supplementation could reduce risk of influenza and COVID-19 infections and deaths. Nutrients. 2020;12:988.

121. Ilie PC, Stefanescu S, Smith L. The role of vitamin D in the prevention of coronavirus disease 2019 infection and mortality. Aging Clin Exp Res. 2020;32:1195-8.

122. Lizneva D, Suturina L, Walker W, Brakta S, Gavrilova-Jordan L, Azziz R. Criteria, prevalence, and phenotypes of polycystic ovary syndrome. FertilSteril. 2016;106:6-15.

123. Huffman AM, Rezq S, Basnet J, Yanes Cardozo LL, Romero DG. SARS-CoV-2 Viral entry proteins in hyperandrogenemic female mice: Implications for women with PCOS and COVID19. Int J Mol Sci. 2021;22:4472.

124. Hägglöf C, Hammarsten P, Strömvall K, Egevad L, Josefsson A, Stattin P, et al. TMPRSS2-ERG expression predicts prostate cancer survival and associates with stromal biomarkers. PLoS One. 2014;9:e86824.

125. La Vignera S, Cannarella R, Condorelli R, Torre F, Aversa A, Calogero A. Sex-specific SARS-CoV2 mortality: Among hormone-modulated ace 2 expression, risk of venous thromboembolism and hypovitaminosis D. Int J MolSci. 2020;21:2948.
126. Zhao Y, Zhao Z, Wang Y, Zhou Y, Ma Y, Zuo W. Single-cell RNA expression profiling of ACE2, the receptor of SARSCoV-2. Am J Respir Crit Care Med. 2020;202:756-9.

127. Hoffmann M, Kleine-Weber H, S, Krüger N, Herrler T, Erichsen $\mathrm{S}$, Schiergens TS, et al. SARS-CoV-2 cell entry depends on ACE2 and TMPRSS2 and is blocked by a clinically proven protease inhibitor. Cell. 2020;181:271-80.e8.

128. Yanes Cardozo LL, Rezq S, Pruett JE, Romero DG. Androgens, the kidney, and COVID-19: an opportunity for translational research. Am J Physiol Renal Physiol. 2021;320:F243-8.

129. Moin ASM, Sathyapalan T, Atkin SL, Butler AE. COVID-19 biomarkers for severity mapped to polycystic ovary syndrome. J Transl Med. 2020;18:490.

130. Moin ASM, Sathyapalan T, Atkin SL, Butler AE. Reninangiotensin system overactivation in polycystic ovary syndrome, a risk for SARS-CoV-2 infection? Metabol Open. 2020b;7:100052.

131. Cadegiani FA, Lim RK, Goren A, McCoy J, Situm M, Kovacevic $\mathrm{M}$, et al. Clinical symptoms of hyperandrogenic women diagnosed with COVID-19. J Eur Acad Dermatol Venereol. 2021;35:e101-4.

132. Stefan N, Birkenfeld AL, Schulze MB, Ludwig DS. Obesity and impaired metabolic health in patients with COVID-19. Nat Rev Endocrinol. 2020;16:341-2.

133. Rottoli M, Bernante P, Belvedere A, et al. How important is obesity as a risk factor for respiratory failure, intensive care admission and death in hospitalised COVID-19 patients? Results from a single Italian centre. Eur J Endocrinol. 2020;183:389-97.

134. Yang Y, Cai Z, Zhang J. Insulin treatment may increase adverse outcomes in patients with COVID-19 and diabetes: a meta-analysis. Front Endocrinol. 2021. https://doi.org/10.3389/fendo.2021.696087.

135. Merad M, Martin JC. Pathological inflammation in patients with COVID-19: a key role for monocytes and macrophages. Nat Rev Immunol. 2020;20:355-62.

136. Bertuccioli A, Balducci D, Bressan A. COVID-19, interleukin-6, androgen receptor and the adipose organ: what are the possible targets of this association? Nutrafoods. 2020;2:176-76.

137. Yang J, Hu J, Zhu C. Obesity aggravates COVID-19: A systematic review and meta-analysis. J Med Virol. 2020;jmv.26237.

138. Williamson EJ, Walker AJ, Bhaskaran K, Bacon S, Bates C, Morton CE, et al. Factors associated with COVID-19-related death using OpenSAFELY. Nature. 2020;584:430-6.

139. Daryabor G, Kabelitz D, Kalantar K. An update on immune dysregulation in obesity-related insulin resistance. Scand J Immunol. 2019;89:e12747.

140. Dhurandhar NV, Bailey D, Thomas D. Interaction of obesity and infections. Obes Rev. 2015;16:1017-29.

141. Tay MZ, Poh CM, Rénia L, MacAry PA, Ng LFP. The trinity of COVID-19: immunity, inflammation and intervention. Nat Rev Immunol. 2020;20:363-74.

142. Brien AO, Kedia-Mehta N, Tobin L, Veerapen N, Besra GS, Shea DO, et al. Targeting mitochondrial dysfunction in MAIT cells limits IL-17 production in obesity. Cell Mol Immunol. 2020;17:1193-5.

143. Parrot T, Gorin JB, Ponzetta A, Maleki KT, Kammann T, Emgård $\mathrm{J}$, et al. MAIT cell activation and dynamics associated with COVID-19 disease severity. Sci Immunol. 2020;5:eabe1670.

144. Stengel A, Goebel-Stengel M, Teuffel P, Hofmann T, Buße P, Kobelt $\mathrm{P}$, et al. Obese patients have higher circulating protein levels of dipeptidyl peptidase IV. Peptides. 2014;61:75-82.

145. Vankadari N, Wilce JA. Emerging WuHan (COVID-19) coronavirus: glycan shield and structure prediction of spike glycoprotein and its interaction with human CD26. Emerg Microbes Infect. 2020;9:601-4.

146. Simonnet A, Chetboun M, Poissy J, Raverdy V, Noulette J, Duhamel A, et al. High prevalence of obesity in severe acute 
respiratory syndrome coronavirus-2 (SARS-CoV-2) requiring invasive mechanical ventilation. Obesity (Silver Spring). 2020;28:1195-9.

147. Stein PD, Beemath A, Olson RE. Obesity as a risk factor in venous thromboembolism. Am J Med. 2005;118:978-80.

148. Sattar N, McInnes IB, McMurray JJV. Obesity is a risk factor for severe COVID-19 infection: Multiple potential mechanisms. Circulation. 2020;142:4-6.

149. Cinti S, Graciotti L, Giordano A, Valerio A, Nisoli E. COVID19 and fat embolism: a hypothesis to explain the severe clinical outcome in people with obesity. Int J Obes. 2020;44:1800-2.

150. Pasquarelli-do-Nascimento G, Braz-de-Melo HA, Faria SS, Santos IO, Kobinger GP, Magalhães KG. Hypercoagulopathy and adipose tissue exacerbated inflammation may explain higher mortality in COVID-19 patients with obesity. Front Endocrinol. 2020;11:530.

151. Frisardi V. Commentary: coronavirus and obesity: could insulin resistance mediate the severity of Covid-19 infection? Front Public Health. 2020;8:351.

152. Zhang JJ, Dong X, Cao YY, Yuan YD, Yang YB, Yan YQ, et al. Clinical characteristics of 140 patients infected with SARSCoV-2 in Wuhan. China Allergy. 2020;75:1730-41.

153. Sepilian V, Nagamani M. Adiponectin levels in women with polycystic ovary syndrome and severe insulin resistance. J Soc Gynecol Investig. 2005;12:129-34.

154. de Medeiros SF, de Medeiros MAS, Barbosa BB, Yamamoto MMW, Maciel GAR. Comparison of metabolic and obesity biomarkers between adolescent and adult women with polycystic ovary syndrome. Arch Gynecol Obstet. 2021;303:739-49.

155. Marazuela M, Giustina A, Puig-Domingo M. Endocrine and metabolic aspects of the COVID-19 pandemic. Rev Endocr Metab Disord. 2020;21:495-507.

156. Emani A, Javanmardi F, Pirbonyeh N, Akbari A. Prevalence of underlying diseases in hospitalized patients with COVID-19: a systematic review and meta-analysis. Arch AcadEmerg Med. 2020;8:e35.

157. Zhou F, Yu T, Du R, Fan G, Liu Y, Liu Z, et al. Clinical course and risk factors for mortality of adult inpatients with COVID19 in Wuhan, China: a retrospective cohort study. Lancet. 2020;395:1054-62.

158. Yang JK, Lin SS, Ji XJ, Guo LM. Binding of SARS coronavirus to its receptor damages islets and causes acute diabetes. Acta Diabetol. 2010;47:193-9.

159. Petrilli CM, Jones SA, Yang J, Rajagopalan H, O'Donnell L, Chernyak Y, et al. Factors associated with hospital admission and critical illness among 5279 people with coronavirus disease 2019 in New York City: prospective cohort study. BMJ. 2020;369:m1966.

160. Gupta R, Ghosh A, Singh AK, Misra A. Clinical considerations for patients with diabetes in times of COVID-19 epidemic. Diabetes MetabSyndr. 2020;14:211-2.

161. Guan WJ, Ni ZY, Hu Y, Liang WH, Ou CQ, He JX, et al. Clinical characteristics of coronavirus disease 2019 in China. N Engl J Med. 2020;382:1708-20.

162. Bornstein SR, Dalan R, Hopkins D, Mingrone G, Boehm BO. Endocrine and metabolic link to coronavirus infection. Nat Rev Endocrinol. 2020;16:297-8.

163. Puig-Domingo M, Marazuela M, Giustina A. COVID-19 and endocrine diseases. A statement from the European Society of Endocrinology. Endocrine. 2020;68:2-5.

164. i MY, Li L, Zhang Y, Wang XS. Expression of the SARS$\mathrm{CoV}-2$ cell receptor gene ACE2 in a wide variety of human tissues. Infect Dis Poverty. 2020;9:45.

165. Rayman G, Lumb A, Kennon B, Cottrell C, Nagi D, Page E, et al. Guidelines for the management of diabetes services and patients during the COVID-19 pandemic. Diabet Med. 2020;37:1087-9.
166. Muniyappa R, Gubbi S. COVID-19 pandemic, coronaviruses, and diabetes mellitus. Am J Physiol Endocrinol Metab. 2020;318:E736-41.

167. Azar WS, Njeim R, Fares AH, Azar NS, Azar ST, El Sayed M, et al. COVID-19 and diabetes mellitus: how one pandemic worsens the other. Rev Endocr Metab Disord. 2020;21:451-63.

168. Ma RCW, Holt RIG. COVID-19 and diabetes. Diabet Med. 2020;37:723-5.

169. Geerlings SE, Hoepelman AI. Immune dysfunction in patients with diabetes mellitus (DM). FEMS Immunol Med Microbiol. 1999;26:259-65.

170. Stokes EK, Zambrano LD, Anderson KN, Marder EP, Raz KM, El Burai FS, et al. Coronavirus disease 2019 case surveillance - United States, 22 Jan - 30 May 2020. MMWR Morb Mortal Wkly Rep. 2020;69:759-65.

171. Guo W, Li M, Dong Y, Zhou H, Zhang Z, Tian C, et al. Diabetes is a risk factor for the progression and prognosis of COVID-19. Diabetes Metab Res Rev. 2020:e3319.

172. Finucane FM, Davenport C. Coronavirus and obesity: could insulin resistance mediate the severity of Covid-19 infection? Front Public Health. 2020;8:184.

173. Knapp S. Diabetes and infection: is there a link?-A mini-review. Gerontology. 2013;59:99-104.

174. Moutschen MP, Scheen AJ, Lefebvre PJ. Impaired immune responses in diabetes mellitus: analysis of the factors and mechanisms involved. Relevance to the increased susceptibility of diabetic patients to specific infections. Diabete Metab. 1992;18:187-01.

175. Hussain A, Bhowmik B, do Vale Moreira NC. COVID-19 and diabetes: Knowledge in progress. Diabetes Res Clin Pract. 2020;162:108142.

176. Al-Musawy S, Al-Saimary I, Flaifil M. Levels of cytokines profile in polycystic ovary syndrome. Med J Babylon. 2018;15:124-8.

177. Rao S, Lau A, So H. Exploring diseases/traits and blood proteins causally related to expression of ACE2, the putative receptor of SARS-CoV-2: A mendelian randomization analysis highlights tentative relevance of diabetes-related traits. Diabetes Care. 2020;43:1416-26.

178. Sharma S, Ray A, Sadasivam B. Metformin in COVID-19: A possible role beyond diabetes. Diabetes Res Clin Pract. 2020;164:108183.

179. Drucker DJ. Coronavirus infections and type 2 diabetesshared pathways with therapeutic implications. Endocr Rev. 2020;41:bnaa011.

180. Kim JJ, Choi YM. Dyslipidemia in women with polycystic ovary syndrome. Obstet Gynecol Sci. 2013;56:137-42.

181. Santos CS, Morales CM, Álvarez ED, Castro CÁ, Robles AL, Sandoval TP. Determinants of COVID-19 disease severity in patients with underlying rheumatic disease. Clin Rheumatol. 2020;39:2789-96.

182. Hu X, Chen D, Wu L,He L, Wei GYe. Low serum cholesterol level among patients with COVID-19 infection in Wenzhou, China. China. 2020.

183. Liu Q, Xie YJ, Qu LH, Zhang MX, Mo ZC. Dyslipidemia involvement in the development of polycystic ovary syndrome. Taiwan J Obstet Gynecol. 2019;58:447-53.

184. Bramante C, Tignanelli C, Dutta N, Jones E, Tamariz L, Clark $\mathrm{J}$, et al. Non-alcoholic fatty liver disease (NAFLD) and risk of hospitalization for Covid-19. medRxiv. 2020.09.01.20185850

185. Kumarendran B, O’Reilly M, Manolopoulos K, Toulis K, Gokhale K, Sitch A, et al. Polycystic ovary syndrome, androgen excess, and the risk of nonalcoholic fatty liver disease in women: A longitudinal study based on a United Kingdom primary care database. PLoS Med. 2018;15:e1002542

186. Zeiser R. Immune modulatory effects of statins Immunology. 2018;154:69-75. 
187. Feldson DS. Treating influenza with statins and other immunomodulatory agents. Antiviral Res. 2013;99:417-35.

188. South AM, Diz DI, Chappell MC. COVID-19, ACE2, and the cardiovascular consequences. Am J Physiol Heart Circ Physiol. 2020;318:H1084-90.

189. Savoia C, Volpe M, Kreutz R. Hypertension, a moving target in COVID-19: Current views and perspectives. Circ Res. 2021;128:1062-79.

190. Tadic M, Cuspidi C, Grassi G, Mancia G. COVID-19 and arterial hypertension: Hypothesis or evidence? J Clin Hypertens (Greenwich). 2020;22:1120-6.

191. Randeva HS, Tan BK, Weickert MO, Lois K, Nestler JE, Sattar $\mathrm{N}$, et al. Cardiometabolic aspects of the polycystic ovary syndrome. Endocr Rev. 2012;33:812-41.

192. Bentley-Lewis R, Seely E, Dunaif A. Ovarian hypertension: polycystic ovary syndrome. Endocrinol Metab Clin North Am. 2011;40:433-X.

193. Reynolds HR, Adhikari S, Pulgarin C, Troxel AB, Iturrate E, Johnson SB, et al. Renin-angiotensin-aldosterone system inhibitors and risk of COVID-19. N Engl J Med. 2020;382:2441-8.

194. Amiri M, Ramezani Tehrani F, Behboudi-Gandevani S, BidhendiYarandi R, Carmina E. Risk of hypertension in women with polycystic ovary syndrome: a systematic review, meta-analysis and meta-regression. Reprod Biol Endocrinol. 2020;18:23.

195. Mancia G, Rea F, Ludergnani M, Apolone G, Corrao G. Renin-angiotensin-aldosterone system blockers and the risk of COVID-19. N Engl J Med. 2020;382:2431-40.

196. Simopoulos AP. Genetic variation, diet, inflammation, and the risk for COVID-19. Lifestyle Genom. 2021;14:37-42.

197. Chiappetta S, Sharma AM, Bottino V, Stier C. COVID-19 and the role of chronic inflammation in patients with obesity. Int $\mathrm{J}$ Obes (Lond). 2020;44:1790-2.
198. Liu M, Gao J, Zhang Y, Li P, Wang H, Ren X, et al. Serum levels of TSP-1, NF- $\mathrm{KB}$ and TGF- $\beta 1$ in polycystic ovarian syndrome (PCOS) patients in northern China suggest PCOS is associated with chronic inflammation. Clin Endocrinol (Oxf). 2015;83:913-22.

199. Han MS, White A, Perry RJ, Camporez JP, Hidalgo J, Shulman GI, et al. Regulation of adipose tissue inflammation by interleukin 6. Proc Natl Acad Sci U S A. 2020;117:2751-60.

200. Arusoglu G, Bozay K. The immune system response in Covid-19 infection in polycystic ovary syndrome. Int J Med Sci Clin Invest. 2021;8:5380-6.

201. Bilezikian JP, Bikle D, Hewison M, et al. Mechanisms in endocrinology: Vitamin D and COVID-19. Eur J Endocrinol. 2020;183:R133-47.

202. Miao CY, Fang XJ, Chen Y, Zhang Q. Effect of vitamin D supplementation on polycystic ovary syndrome: A meta-analysis. Exp Ther Med. 2020;19:2641-9.

203. Cunningham TK, Allgar V, Dargham SR, Kilpatrick E, Sathyapalan T, Maguiness S, et al. Association of vitamin D metabolites with embryo development and fertilization in women with and without PCOS undergoing subfertility treatment. Front Endocrinol (Lausanne). 2019;10:13.

204. Laird E, Rhodes J, Kenny RA. Vitamin D and inflammation: Potential implications for severity of covid-19. Ir Med J. 2020;113:81.

Publisher's note Springer Nature remains neutral with regard to jurisdictional claims in published maps and institutional affiliations. 